\title{
Educational Partnerships towards Long-Term Music Education Projects in Thailand
}

\author{
Nicha Chansitthichok ${ }^{1}$, Anak Charanyananda ${ }^{2}$, Narongchai Pidokrajt ${ }^{3}$ \\ College of Music, Mahidol University \\ Phutthamonthon Nakhonpathom, 73170 Thailand \\ e-mail: 1nicha.musiced@gmail.com, ${ }^{2}$ ohanak2@gmail.com, ${ }^{3}$ narongchai.rajt@gmail.com \\ DOI: https://doi.org/10.37134/mjm.vol8.6.2019
}

Published online: 15 December 2019

Cite this article (APA): Chansitthichok, N., Charanyananda, A., \& Pidokrajt, N. (2019). Educational Partnerships towards

Long-Term Music Education Projects in Thailand. Malaysian Journal of Music, 8, 96-107.

https://doi.org/10.37134/mjm.vol8.6.2019

\begin{abstract}
There are many challenges in developing long-term music education projects in Thailand such as human resource development, educational policies and financial problems. This study examined the various educational partnerships and workflow plan used to sustain long-term music education projects in Thailand. Findings were based upon the roles and responsibilities of members and the understanding of the workflow plan of music educational partnerships towards the sustainability of music projects. This qualitative research consists of in-depth interviews with 20 informants which comprised music educators, school principals, and community leaders. Two long-term music education projects were discussed and compared in this article. An expert focus discussion group was used to evaluate the validity and reliability of this research. Results showed that strong bond relationships developed in the respective state of educational partnerships to create long-term music education projects. The educational partnership comprised proactive music educators, music teachers, music supervisors, supportive parents and community leaders who worked together to provide the best practices for the students. This partnership can be sustained through various partnership programmes, and the well-being of working together. This study benefits the development of long-term music education in future partnership projects.
\end{abstract}

Keywords: long-term music education project, music educational partnership, Thailand music education

\section{Introduction and Background}

Educational partnerships in music education are geared toward collaboration among public schools, higher institutions and communities within the framework of the education policy. Representatives from the community are chosen to form the board of school committee, and relationships between music teachers and university professors were fostered during music teachers' development programmes in music education partnership projects.

In Thailand, schools, local communities and private sectors have been working together toward the nation's educational development programme. Thailand's 12 leading private companies, schools and communities managed many educational projects. For example, Pracharat School, which is in partnership with the Education Ministry, Ministry of Science and Technology, Ministry of Digital Economy and Society to develop a project called 'ConnextEd' (Thadaphrom, 2018). In 2018, the community formed the 'Thailand Educational Partnership' to focus on educational transformation and change. During the first 'Thailand Educational Partnership Conference' held in May 2018, all the partners from different provinces in the country, as well as those involved in education sectors (such as teachers, school principals, students, higher education professor and educators) gathered to show their commitment and support toward developing education policies 
in Thailand. They also shared the problems faced in schools and real-life situations, which were barriers and limitations towards educational development (Thailand Development Research Institute, 2018).

In 2017, the government initiated the Thai music trophy award to encourage and support music education. This award was presented to schools that demonstrated the best practices in music education programmes (Jiasakul \& Srikhamhaeng, 2018). The music award also encouraged the school's principal and music teachers to join music competitions, and focus their attention towards music activities in school. Joining music competitions improved the students' musical skills and the music teachers' efficacy in teaching music (Tissadikun, 2013). The Ministry of Education also supported music education in schools by introducing an art programme (with a music major) in the high school curriculum (Runggon \& Lohitsatien, 2017). The introduction of the art programme enhanced the quality of teaching and learning music in public schools.

\section{Problem Statement}

Thailand's music education has been steadily developing since 1934. Music institutes and departments in universities were established to serve the needs of music studies in higher education (Thuntawech \& Trakarnrung, 2017). The highest music degree that was first established was a doctoral degree at Mahidol University in 2005. At the same time, there were issues regarding the students' inability to graduate with a doctoral degree in music. One of the main problems was the student's music education background and literary skill (Saibunmi \& Trakarnrung, 2016). This implies that fundamental music education needs to be cultivated along with the development of higher music education.

In contrast to tertiary education, the education policy also shows some weaknesses in the organisation of the music education curriculum. In the university admission system, the music subject was not included in the national testing and assessment (The National Institute of Educational Testing Service, 2019). As a result, the schools tend to ignore the music subject, which led to less attention from school principals and teachers in support of music education in the school.

The music education curriculum in schools comprised the formation of musical ensembles such as marching band, pop band, Thai classical music band, and Thai folk music band. A pre-survey of this research conducted with ten public school music teachers from different regions demonstrated similar problems such as a lack of support from the school's principal, insufficient budgets and inadequate musical instruments as well as lack of competency from music teachers in conducting the music bands.

Previous findings in promoting Thai music demonstrated a lack of support from the school's principal (Thepsongkrau, 1996). The score concerning human resource development was rated the lowest while the budgeting of musical instruments were averagely scored in the findings (Nopsiri \& Gesthong, 2013). According to Vannatham \& Ngamsutti, (2016), success in Thailand music education projects greatly depended on the music teachers and students, supporting factors from the school's principal and parents as well as financial factors in budgeting and providing sufficient musical instruments.

This research focused on developing music education by creating educational partnerships in the community instead of relying on the support from the government educational organisation.

\section{Research objectives}

The aim of this research is to 1) identify the different educational partnerships and the respective roles of its members in supporting long-term music education projects 2) examine the various workflow plans conducted to sustain long-term music education projects. 


\section{Literature review}

\section{Educational partnership}

Educational partnership can be defined as a group of people working together with the same goal or mission in developing or supporting the education system. The conversation and discussion made within the group should be beneficial for every partnership, and there should be an agreement in planning the process of the educational project. The educational partnership should be conducted to achieve the best results for the students. The formal and informal structure between the partnerships could be developed to achieve the education goals (CoxPetersen, 2011). The partnership of a successful educational project comprised seven key components which are 1) prioritising student benefits as a common agenda 2) having leadership in every level of partnership to ensure the sustainability of the project 3 ) having a proper configuration as the success of a project depends on the right workflow plan chosen by the partners according to the context 4) developing integration among the partnership from limited collaboration to sharing more resources and activities 5) having an action in implementation towards sustaining educational project 6) having excellent communication within the partnership and social well-being and 7) using the data and evaluation effectively (Asera, Gabriner \& Hemphill, 2017). There is no single pattern in educational partnership that can fit all situations and environments. It is essential for the partners to be committed and involved in the collaboration to achieve the goals (Tushnet, 1993). The collaboration of educational partnerships may be extended to regional or nationwide. The differences in rural and urban culture do not hinder partnerships if they form good collaborations. They can share their similarity and differences in solving problems and working together to achieve their goals (Moriarty \& Gray, 2003).

\section{Roles and Development of Educational Partnership}

There are various combinations of members in an educational partnership and each played specific roles and responsibilities. Parents play a significant role in the education direction of the students. Parents' involvement towards the learning process reduces the differences between the learning environments in schools and at home, which further motivates the students to perform better in their academic performances (Oostdam \& Hooge, 2013). In the 'community development model' (Stefanski, Valli \& Jacobson, 2016), successful partnership between parents and community in sharing, discussing and solving problems, as well as planning educational issues initiated good relationships between the parents and educators, and thus developed powerful social networking in the community.

In developing effective educational partnerships, clear objective given by the partnerships were important towards the coordination of a project and its execution during the implementation stage. The commitment and support from the leaders of each partnership were necessary in creating trust and a sense of togetherness. The exchange in vision, experiences, and decision making among the partners were the factors in developing and sustaining the projects. Cunningham \& Tedesco (2001) state that effective educational project requires time to develop and years to achieve success. The success factors in arts education comprised excellent collaboration among the different educational partners, teacher readiness, administrative support, and a strong commitment to developing arts education among the partnerships (Andrews, 2011).

According to Pitupumnak (2017), the music culture, identity, history, and socialisation of the people in the community is an important part of music education. Local musicians transferred musical traditions to the people in the community and created a learning environment that involved the whole community. Collaboration between music educators in school and local musicians are important toward the sustainability of traditional music in long-term music education projects

\section{Methodology}

In-depth interviews related to educational partnerships and their roles to support long-term music education project was conducted among those working in the government sector only. The samples were active participants who were involved in music projects within the three years (2016-2018). The 20 interviewees 
(categorised by career and social role) comprised education officers, community leaders, school principals, music supervisor, music teachers, and music educators from the universities. Semi-structured questions were used to investigate the roles and responsibilities of members in the educational partnership and the ways to sustain music education projects. Interviews were conducted according to the following guidelines 1) the roles and responsibilities of partnership in music education projects and 2) the workflow plan used to sustain the long-term music education project. Data collected from the in-depth interviews were transcribed and sent back to the informants for validation.

Two cases were selected for the study of workflow plans in the educational partnership to support longterm development in the music education project. The chosen cases were from well-known projects, such as The Yala City Municipality Youth Orchestra (established in 2006) and the Banthacha-om School Music Project (established in 2008). The Ministry of Culture recommended these cases. The criteria of the chosen samples encompassed 1) being active in any music education project within three years (2016-2018) 2) working in a government organisation. 3) duration of the music education project over a span of at least ten years 4) music education projects operated by a government organisation. Data was collected between September to December 2018. This focus group was used to ensure the validity of this research, and to identify the roles and ways to sustain the long-term music education projects. Eight experts were invited to participate in the focus group. They discussed the partnership's roles and the workflow plan used in their respective educational partnerships. Further discussions included ways to sustain the music education projects in the context of Thailand's education system. The participants in the focus group represented four categories of samples that were related to the music education project such as music educators, a representative from the Ministry of Education, community leaders and music teachers.

\section{Research findings}

The findings in this research are summarised into two sections 1) the roles of music education partnership and 2) the workflow plan used to sustain the music education projects.

\section{The Educational Partnership in Music Education Projects}

The mentioned partnership consisted of students, parents, music teachers, school principal, supervisors (music), music educators and community leaders. The roles and activities of each partnership are described as follows:

\section{Students}

Students involved in musical engagements such as participating in music competition and performing in local community events. Involvement of students in musical competitions also increased their interest in practicing music without the supervision of an adult. The students learned about time management in between studying and playing music. During the music competitions, students also learned to control their emotions in cases of victory or defeat in the competition. The students' interest in music were motivated by their seniors who participated in musical activities in their school. The development of a musical environment in the school also cultivates proper attitude and enthusiasm among the students in learning music.

\section{Parents}

Parents showed their support in the music project after watching their children's performances in local community events such as Buddhist ordination, wedding ceremony and funeral. Parents appreciated the benefits gained in learning music as long as it did not interfere with their children's academic achievements. Their support was given in the form of donation or inviting the students to perform in community events. The parents also consented to the practice schedule, which may be after school or during the weekend. 


\section{Music teacher}

The music teacher played a pertinent role in scheduling musical events, music practice and learning time for the students. Proactive music teachers created long-term music projects. The music teacher need not be an expert in music but is required to have basic musical skills and a positive attitude towards professional development pathways.

The performance of the musical band in schools generally focused on its uniqueness to attract public attention, therefore the music teacher plays an important role in creating the uniqueness of the band. The music teacher also collaborated with the school's principal and community leaders in developing the school's music band. The music teacher also created a bond with her colleagues to enable them to relent to her request as the schedule for music practice and performances may sometimes interrupt with their teaching and learning time.

\section{School principal}

The school principal played an active role in supporting the learning of music in his/her school. The development of a musical environment in the school is vital in creating long-term music education projects. The school's principal mission also included encouraging music teachers and other pedagogues in the school to appreciate the importance of music, and to incorporate music into teaching and learning other subjects. It is also essential for the school's principal to support music teachers to attend professional development course and gain support from other educational partnerships. Professional development is needed for the music teachers to improve on their musical skills in order to further contribute towards long-term music project.

\section{Supervisor (music)}

The music education supervisor played a part in supporting the professional development of the music teacher. The supervisor provided beneficial information regarding the availability of musical events to enable the music teachers to develop their career pathway besides acting as the coordinator between the Ministry of Education and music teachers. The partnership between the supervisor and music teachers contributed towards the sustainability of the music project.

Having a good understanding of the constraints faced by the music teachers in schools, the supervisor also played an important role in delivering their problems to the music educator and school principal in order to enable them to support the music teachers towards better achievement in their career development.

\section{Music educator (in university)}

The music educator may not be directly involved with every partner but acquires substantial knowledge regarding the relationship between every educational partnership. The music educator supported long-term music project by providing knowledge and opportunities to improve on the musical project. The music educator's task included preparing possible music carrier pathways for students interested to pursue in music. The music educator collaborated with the music teacher to recommend possible music careers for the students.

The music educator, as a music teacher trainer, took a vital role in promoting a positive mindset for the music teachers by encouraging them to develop their skills and efficacy in music by attending the teacher training program. Music teachers were often burdened with other responsibilities and duties in public schools and it may cause them to develop a negative mindset towards their school's principal and education supervisor. Hence, it is pertinent for the music educator to promote music teacher training programmes to motivate them.

\section{Community leader}

The community leader acquired the advantage of having a music band in the community to foster unity amongst its people. The local music band represented the local identity and culture, which further contributed towards a united community. With the knowledge to raise funds from governments and communities, as well as create musical events or competitions, the community leader worked directly with the government and local people. 
The community leader supported the school's musical programmes on local traditional culture to develop both the children and their parents' attitude towards music.

Targeting local musicians who are the community's intangible cultural heritages facilitated the sustainability of music education projects. The local musicians in the community acted as music educators, and contributed in transmitting the local musical culture to the next generation, hence being part of the educational partnership.

The connection from these educational partnerships supported long-term musical education project by prioritising students' benefits. For example, the students gained the support from their music teacher and parents to participate in the community's musical events that were arranged by the community leader. The sustainability of the music education project in the society depends on the strength of relationship and teamwork among each partnership. The willingness of the educational partnership in the community to keep track of the educational objectives, making decisions and solving problems together further enhanced the success in continuing the music education project in schools.

\section{Educational Partnership to Support Long-Term Music Education Project}

Two music education project cases were selected for the study of its organisation and workflow as well as the sustainability of its music project for over ten years

\section{Yala City Municipality Youth Orchestra}

Yala is the southernmost province of Thailand. In 2006, the mayor of Yala, Pongsak Yingchoncharoen established the 'Yala City Municipality Youth Orchestra' project to 1) encourage the children of various ethnic and religious diversity to play music together 2) invoke peace and order among the children in the society, Music educator, Weerasak Aksornteang, who teaches music at Songkhla Rajabhat University, was invited by the mayor to form a symphony orchestra. At the initial stage of the project, the music teachers were incompetent in teaching the musical instruments in the symphony orchestra. Hence, the musicians and professors at the College of Music, Mahidol University were invited to train Yala music teachers in the professional development programme. An exhibition on western musical instruments was displayed to educate the people of Yala on the instruments of a symphony orchestra.

The first musical concert was performed in celebration of King Rama IX's birthday. The repertoire, which included classical music, Thai traditional music and local music made the people of Yala proud of their culture and lifted the spirits of the local people. The success of the first concert created a huge impact on the Yala people. The children from different religions were seen performing music together, and they fostered closer relationship among each other. Parents supported the project by allowing their children to attend and participate in the musical events. The partnership between the school's principal and music educators from the university further provided more opportunities for the children to pursue higher education in music. The workflow plan to create the long-term music education project in Yala is shown in Figure 1.

The workflow plan of Yala's case study demonstrated that the community leader initiated the music project, worked with the music educator (from the university) on the project possibilities and planned the workflow of the project together. The music teachers from the public schools were invited to join the music project voluntarily and the community leader supported their engagement. After attending the professional development course conducted by the music educators, the music teachers recruited students from their schools to join the music project, taught them to play the musical instruments and conducted rehearsals. The music teacher played a part in convincing the parents by showing them the benefits of joining the music project. Finally, with excellent support from the parents and community, the students showcased their performance to the people of Yala. The community leader played a direct role in encouraging the people of Yala to join the event as audiences as well as contributing and supporting the project. 


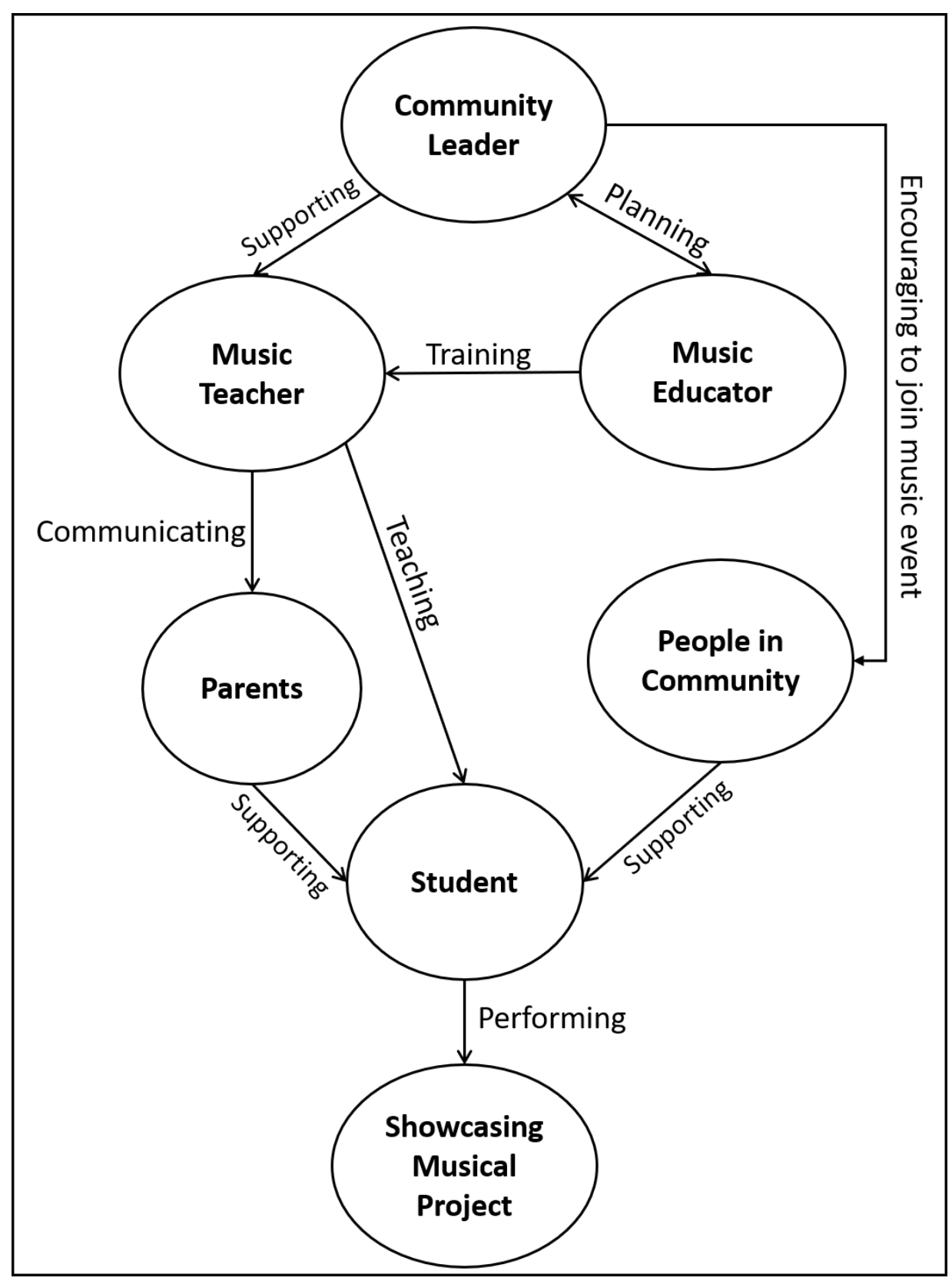

Figure 1. Partnership workflow of music education project in 'Yala'

\section{Music Education Project in Banthacha-Om School, Utai Thani Province}

The Banthacha-om School is located in Utai thani Province. The school was awarded the 'Complete Thai Music Teaching in Schools' by the Ministry of Culture in 2017. The school's principal, Wichian Laothiang, was the pillar behind the achievement of the school's music project. He started the project by establishing a small musical ensemble in the school to play for their school's events. He personally taught the school band during lunch breaks and after school every day. Music was taught in a music room, which was specifically located at center of the school to enable every child from all ages (kindergarten to primary school) to listen and appreciate the music. The musical environment provoked the passion for learning music among the children. The children were always taught new songs and they performed for social occasions and functions. The band's performances were unique, and the children always dressed very smartly in every performance, which made their parents 
proud and supportive of the music project. The school was renowned in its band performances, and was invited to perform for community events, which further gained support from the community.

2.

The workflow chart to create the long-term music education project in Banthacha-om is shown in Figure

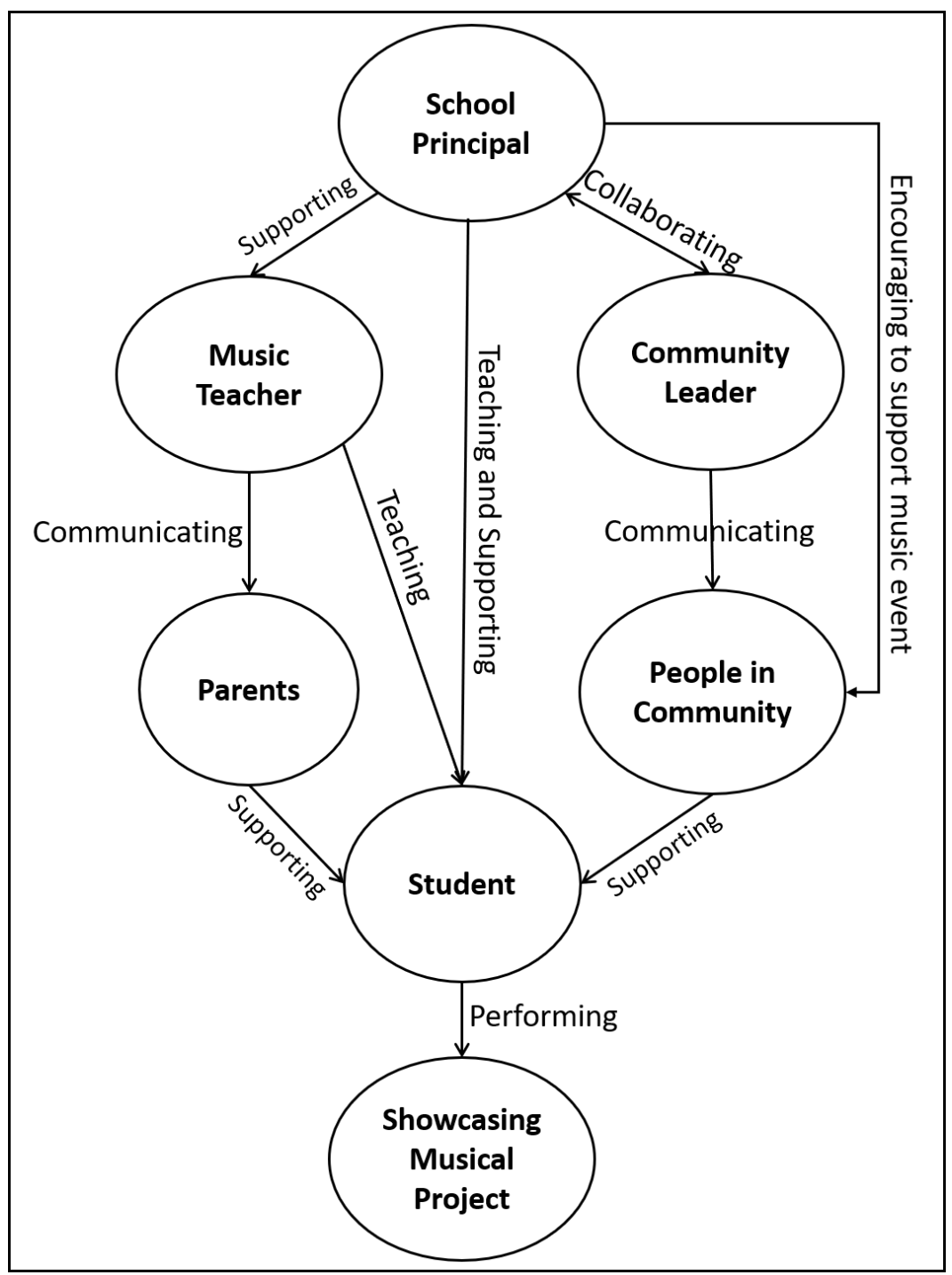

Figure 2. Partnership workflow of music education project in Banthacha-om

\section{Discussions}

\section{Roles of the Different Partnerships}

Different types of partnerships were used to initiate long-term musical projects in the community. The person who initiates the music project may be from any form of partnership, but should have strong passion for creating a music educational environment in the community. This active collaboration allowed partners to further motivate the other partners in the music education project.

Long-term music education projects need strong collaboration among every supporting partner in the education system. The Thailand education system comprised many organisations such as the organisation in 
the Ministry of Education, the teacher training university, the local administration organisation and people within the community. These partners played an important role in the music education system.

Research findings demonstrated that the different partnership's state and roles in supporting long-term music education projects could be grouped into three categories: (refer to Table 1)

1. Active state: Students who participated in the music projects. The student who is willing to learn music, appreciate music and play music. This active state may be influenced by other factors such as parents and the music teacher.

2. Proactive state: Music teachers, music educators, and music supervisors thriving for the best plan and result in the music education project. The music teacher and music educator need to be proactive in conducting musical activities and building relations within the partnership in the music education project.

3. Supportive state: parents, school principals, community leaders and people in the community who supported the learning of music in the community. Parents contributed to the expenses of learning music such as buying musical instruments and paying for music lessons. The school's principal and community leaders played an important role in promoting music activities and raising funds to run the musical events regularly. The positive outcomes contributed to the sustainability of the rich musical culture of the community and its uniqueness.

Each partnership took on a specific role to support the development of long-term music education. The sustainability of the music education project occurred when there is a good relationship within each partner to support each other. The initial partnership of the music education project may be initiated by two partners and eventually increases in numbers. The essential key to success in the music project is its effectiveness in attracting the participation of all partners although they may not be involved directly in the active state. Effective partnership is required in promoting music education in the community. The music educator may use the concept of educational partnership to develop long-term educational projects.

Table 1.

Roles and responsibilities of partnerships in sustaining music education projects

\begin{tabular}{ccc}
\hline Categories & Partnership & Roles \\
\hline Active state & Student & $\begin{array}{c}\text { Willing to learn music, appreciate } \\
\text { music and has a passion in playing } \\
\text { music }\end{array}$ \\
Proactive state & $\begin{array}{c}\text { Music teachers } \\
\text { Music educators } \\
\text { Music supervisors } \\
\text { Supportive state }\end{array}$ & $\begin{array}{c}\text { Planning the best actions and the best } \\
\text { results for the music project }\end{array}$ \\
& $\begin{array}{c}\text { Parents } \\
\text { School principal community leader } \\
\text { People in the community }\end{array}$ & $\begin{array}{c}\text { Supporting the teaching and learning } \\
\text { of music in the community }\end{array}$ \\
\hline
\end{tabular}

Parents played an important role as one of the educational partnerships to support the learning of music (Suriyonplengsaeng \& Trakarnrung, 2015). Without the support from the parents, direct support from the music teacher may be insufficient for long-term music projects. Parents expected music teachers to be friendly and provide sound advice for the students in developing their musical pathways (Ang, Panebianco \& Odendaal, 2019). This study showed similar preferences on the roles of parents and music teachers to support long-term music education project.

As one of the school's committee, the community leader attended the school's meetings, and involved in planning the music project, supporting and following-up the project as well as evaluating the school's education plan (Phuangsomjit, 2017). The music teacher collaborated with the school's principal to develop a 
long-term music project and presented it to the school's committee. The music project further gained support from the leader and people in the community.

The music educator, music teacher, university professor, and music supervisor may use the idea of educational partnership to develop long-term music education programmes in their annual music teachertraining course. The university professor may design a standard music professional development course for Kurupatana organisation (a teacher professional development institute, which was established in 2017) following the aims of the national education plan. This organisation is responsible for affirming the teacher professional development course if it is used to promote the academic position of the teachers (Objective of Kurupatana, 2017). The course contents included three areas of professional development for the music teachers such as knowledge, skills, and code of ethics (Chaisupa, 2017). The university's professor or senior supervisor is required to conduct the course and share their expertise with the music teachers. The course benefitted the music teachers who will be developing the music project in school. Planning of the music project could be done through educational partnerships music teacher, music educator (in university), and music supervisor. The relationship among the partners could be enhanced through professional development courses, which will eventually motivate the music teacher's state to be a proactive music teacher.

\section{Comparisons of the Two Cases}

The workflow plan of the educational partnerships from the two cases revealed differences in relationship and directions. In the case study of Yala's education partnership, the community's leader is able to initiate the project between the community and education sector because of the strong relationship between the community leader and people. Therefore, the workflow plan started from the community leader to the music educator and the people in the community. On the other hand, the school principal in Banthacha-om music project had the musical skills to organise and develop the music education project in school and showcased it to the community to gain support. Therefore, the workflow plan of the music education project was initiated from school principal to the music teacher, students, and finally reached the community. The different workflow plans may be based on the willingness of different educational partnerships in the community to accept music education projects. This research showed that problems related to human resources affected the development of music education projects (Thepsongkrau, 1996). Motivating partnerships among them may solve these problems.

The research also demonstrated financial problem was not an issue in the long-term music education project (Nopsiri \& Gesthong, 2013). Successful long-term music education project gained monetary support when partnerships were in an active state and the community supported the music projects. Donations from people in the community were enough to sustain the music education project. The findings from these cases are examples of best practices in workflow plans and partnership in organising long-term music education project. These findings may be used to develop other music projects in the future.

\section{Conclusion}

The key factor to sustain music education projects is to collaborate with different partnerships. It can be inferred that long-term music education projects may not be achieved only through educational partnership in the community for good relationships among the partners were also needed to sustain a proactive musical environment. A government music education project without collaboration with various partnerships may not be successful. This study hopes that the government educational agency will enable them to expand the concept of education partnerships, improve the relationship of various partners, and gain financial support from the government. The music educator in the university may use the findings to conduct collaborative programmes with the university, community, school, music teacher, and students. The area of partnership could be extended towards private sector to gain further partnerships in the music education project. 


\section{References}

Andrews, B. (2011). The good, the bad, and the ugly: Identifying effective partnership practices in arts education. International Journal of Humanities and Social Science, 1(13), 38-46.

Ang, K., Panebianco, C., \& Odendaal, A. (2019). Exploring the role of the music teacher from the perspectives of parents and teachers in West Malaysia. Malaysian Journal of Music, 8, 52-67.

Asera, R., Gabriner, R., \& Hemphill, D. (2017). Starting and sustaining educational partnerships. Retrieved from https://collegefutures.org/wp-content/uploads/2017/04/Starting-and-Sustaining-Ed-Partnerships-2017.pdf

Chaisupa, N. (2017). W22/2560 Rules and framework for teacher and educator. Retrieved from http://www.otepc.go.th /index.php/notice-lawrule/circularnotice/1892-22-2560.

Cox-Petersen, A. (2011). Educational partnerships. Los Angeles, CA: SAGE.

Cunningham, L., \& Tedesco, L. (2001). Mission possible: Developing effective educational partnerships. Journal of Higher Education Outreach and Engagement, 7(1\&2), 79-89.

Jiasakul, S., \& Srikhamhaeng, N. (2018). School model: 100\% Thai music. Bangkok: Ministry of Culture.

Moriarty, B., \& Gray, B. (2003). Future directions: A model for educational partnerships in Australia. Journal of Research in Rural Education, 18(3), 159-163.

Nopsiri, S., \& Gesthong, T. (2013). The promotion of teaching Thai music in primary schools of the office of NakhonSawan primary education service area 2. Retrieved from http://www.old.nrru.ac.th/grad/UserFiles /File/NIRC2013/OED018.pdf

Objective of Kurupatana. (2017). Retrieved from http://www.kurupatana.ac.th/

Oostdam, R., \& Hooge, E. (2013). Making the difference with active parenting; forming educational partnerships between parents and schools. The European Journal of Psychology of Education, 28(2), 337-351. doi:10.1007/s.10212-012-0117-6

Pitupumnak, K. (2017). Content and teaching-learning process in community music education in Chiangmai province, Thailand. Journal of Fine Arts, Chiang Mai University, 8(2).

Phuangsomjit, C. (2017). Establishing school - Community relationships. Veridian E-Journal, Silpakorn University, 10(2), 1342-1354.

Runggon, I., \& Lohitsatien, B. (2017). Open music Classroom. Retrieved from https://www.moe.go.th/moe/th/news/ detail.php?NewsID $=48425 \&$ Key=newsSurachet

Saibunmi, S., \& Trakarnrung, S. (2016). Barriers to Thai Doctoral Music Students' Socialisation. Malaysian Music Journal, 5(2), 36-53.

Stefanski, A., Valli, L., \& Jacobson, R. (2016). Beyond involvement and engagement: The role of the family in schoolcommunity partnerships. School Community Journal, 26(2), 135-160.

Suriyonplengsaeng, C., \& Trakarnrung, S. (2015). Parent and teacher partnership in supporting children musical learning. Fine Arts International Journal, Srinakharinwirot University, 19(1), 65-73.

Thadaphrom, T. (2018). PM Prayut chairs signing of MOU to promote participatory culture. Retrieved from http://thainews.prd.go.th/en/news/detail/WNOHT6109130010001

Thailand Development Research Institute. (2018). Reform showcase: Education 4.0. Retrieved from https://tdri.or.th/2018/04/

The National Institute of Educational Testing Service (Public Organisation). (2019). Retrieved from https://www.niets.or.th/en

Thepsongkrau, J. (1996). A study of factors of Thai classical music in secondary schools in the south influencing the participation in the contest of Thai classical music promotion in the south. Parichart Journal, Thaksin University, 9(2), 77-85.

Thuntawech, S., \& Trakarnrung, S. (2017). The Ideal Characteristics of Higher Education Music Institutes in 21st century Thailand. Malaysian Music Journal, 6(1), 30-49.

Tissadikun, N. (2013). Symphonic band rehearsal in high school level for competition. Journal of Fine and Applied Arts Khon Kaen University, 5(2), 127-147.

Tushnet, N. (1993). Guide to developing educational partnerships. Washington, DC: The Program.

Vannatham, N., \& Ngamsutti, C. (2016). The way to be excellence of secondary school luk thung band in Thailand. Retrieved from https://www.tci-thaijo.org/index.php/jica/article/download/99322/77191/ 


\section{Biography}

Nicha Chansitthichok is a Ph.D. candidate in music education from the College of Music, Mahidol University, Thailand. She has received a Master of Arts (Music) in Music Education from the College of Music, Mahidol University, and Bachelor of Economics from Chulalongkorn University, Thailand. She is currently a private studio teacher at Sounds Good Piano Studio, Bangkok, Thailand. She has been teaching music for early childhood and private piano class since 2006. Her areas of interests include topics in music education, music for leisure, music in higher education, and music in lifelong learning.

Anak Charanyananda, Ph.D is an Assistant Professor of Music at Mahidol University College of Music. He teaches and researches in music education and musicology at the College of Music, Mahidol University, where he has worked since 1994. He regularly gives lectures on western music history, studies of world music, music teacher education and musicological fieldwork, as well as seminar in music research, form an analysis, and counterpoint. Charanyananda received his Ph.D. in Music from the College of Music, Mahidol University. He holds a Master Degree in Musicology from the University of the Philippines College of Music and a Bachelor Degree in Music Education from Bansomdej Chaophrya Teachers'college, Department of Teacher training, Ministry of Education, Thailand.

Narongchai Pidokrajt, Ph.D is an Associate Professor of Music at Mahidol University College of Music. He teaches and researches in music education and musicology at the College of Music, Mahidol University, where he has worked since 1996. He regularly gives lectures on Thai music theory and history, and musicological fieldwork, as well as seminar in music research. Pidokrajt received his Ph.D. in Music from the College of Music, Mahidol University. He holds a Master Degree in education (Higher Ed.) from Srinakharinwirot University (Southern campus) and Master of Arts (Music) from Mahidol University, Thailand. 